\title{
Espacios públicos no tan públicos
}

\section{Public spaces not so public}

\section{Laura Lozada Acosta (*) \\ Congreso de la República del Perú \\ ORCID: 0000-0002-4285-7825}

Fecha de recepción: 16 de febrero

Fecha de aceptación: 14 de junio

\section{ISSN en línea: $2415-2498$}

Lozada Acosta, L. (2018) «Espacios públicos no tan públicos». Politai: Revista de Ciencia Política, Año 9, primer semestre, № 16: pp. 75-109.

DOI: https://doi.org/10.18800/politai.201801.003

* Asesora en agenda urbana de la congresista por Lima Indira Huilca. Ha trabajado en temas de vivienda y renovación urbana en la Municipalidad Metropolitana de Lima. Es magíster en Desarrollo Urbano y Regional por la Universidad de Seúl, y bachiller en Economía por la Universidad del Pacífico. La autora agradece a las y los vecinos del Parque Manhattan que compartieron con ella su caso. Así también, agradece a Alonso Hidalgo y Daniel Ramírez-Corzo por sus comentarios. lauralozada88@gmail.com 


\section{Sumilla}

Lima está experimentando una serie de conflictos generados por iniciativas privadas que proponen el desarrollo de plataformas comerciales, estacionamientos y otras formas de aprovechamiento privado sobre parques y áreas verdes de la ciudad. Las iniciativas que intervienen en los espacios públicos se amparan en un ordenamiento jurídico que privilegia la promoción de la inversión privada y que, a la vez, encuentran una gran acogida en los gobiernos locales, que buscan nuevas fuentes de ingreso aún a costa de la desnaturalización de lo público. A través de dos casos de conflictos, el Parque Manhattan en Comas y la Alameda Los Incas en Independencia, se analiza la influencia que ejercen la regulación pública y las lógicas de inversión del capital privado sobre los espacios públicos, así como las medidas que adoptan los gobiernos locales y los movimientos ciudadanos. Se analiza también el arreglo de toma de decisiones sobre el ámbito de la gestión de los espacios públicos y qué asimetrías de poder existen entre quienes participan del mismo. Se concluye que el actual arreglo privilegia la participación del gobierno local y las empresas privadas en la determinación de qué se hace en el suelo de uso público, dejando de lado la voz de los vecinos. No obstante, los casos demuestran el poder de la movilización ciudadana para frenar este tipo de iniciativas privadas en los espacios públicos.

Palabras clave: espacios públicos, iniciativas privadas, gobernanza urbana 


\begin{abstract}
Lima is experiencing a series of conflicts generated by private initiatives that propose the development of commercial platforms, parking lots and other forms of private investment on parks and green areas of the city. These initiatives are based on a legal system that favors the promotion of private investment. They also find a great reception in local governments, which seek new sources of income even at the expense of the denaturalization of the public. The article takes two cases, the Manhattan Park in Comas and the Alameda Los Incas in Independencia, to analyze the influence of public regulation and the logic of private capital on public spaces, as well as the measures adopted by the local governments and citizen movements. Also, it analyzes the decision-making arrangement on the public space management and what power asymmetries exist among those who participate in it. It is concluded that the current arrangement favors the participation of local government and private companies in the determination of what can be done on the land of public use, leaving the voice of neighbors aside. However, the cases demonstrate the power of citizen mobilization to stop this type of private initiatives in public spaces.
\end{abstract}

Keywords: public spaces, private initiatives, urban governance 


\section{Introducción}

Los espacios públicos son áreas de la ciudad destinadas - por su naturaleza, uso o afectación - a la satisfacción de necesidades urbanas colectivas. Son al mismo tiempo telón de fondo e hilo conductor entre la ciudad y la ciudadanía. Como bien señala Cabrera y Villaseca (2007), en los espacios públicos queda la huella física de las relaciones entre las personas de una sociedad. Así también, Jordi Borja los define de la siguiente manera:

El espacio público expresa la democracia en su dimensión territorial. Es el espacio de uso colectivo. Es el ámbito en el que los ciudadanos pueden (o debieran) sentirse como tales, libres e iguales. El donde la sociedad se escenifica, se representa a sí misma, se muestra como una colectividad que convive, que muestra su diversidad y sus contradicciones y expresa sus demandas y sus conflictos. Es donde se construye la memoria colectiva y se manifiestan las identidades múltiples y las fusiones en proceso. (Borja 2012, 205)

En Lima Metropolitana, los espacios públicos tienden a ser valorados y caracterizados por sus áreas verdes. En la metrópoli de Lima-Callao existen 3 207 hectáreas de áreas verdes públicas ${ }^{1}$. De estas, el 52\% corresponde a parques distritales y le siguen en importancia los parques lineales o bermas con un 22\%. Los parques distritales son el medio de acceso más importante de áreas verdes para los limeños. Estos espacios también son preferidos para la localización de viviendas. Según el informe de las edificaciones urbanas en Lima Metropolitana y el Callao de Capeco 2017, el 31.59\% prefiere la ubicación frente al parque, en todos los rangos de precios de viviendas y sobre otras características de ubicación ${ }^{2}$.

\footnotetext{
1 Se contabiliza todas las áreas verdes públicas, habilitadas o no, y las zonificadas en Zonas de Recreación Pública (ZRP) y Otros Usos (OU). Información producida por el equipo del PLAM2035 (MML, 2014) en base al inventario de la MML de 2013.

${ }^{2}$ Las otras características de ubicación de la vivienda son cerca de centro comercial, en avenida, en calle poco transitada, en condominio cerrado, frente al mar y otros.
} 
Si bien los espacios públicos verdes son preferidos, su provisión está en déficit. En promedio en Lima-Callao, tenemos $3.6 \mathrm{~m} 2$ de áreas verdes públicas por habitante. Frente a este déficit y al crecimiento poblacional, los espacios públicos existentes tienen una mayor presión de uso.

En este contexto, los capitales privados han desarrollado nuevos mecanismos de extracción de renta a partir del suelo urbano. Los marcos legales de promoción de la inversión privada, que inicialmente fueron pensados para grandes proyectos de infraestructura (en el caso peruano, diversas modalidades de asociación público-privada), ahora son usados en el nivel local para el desarrollo de plataformas comerciales, estacionamientos y otras formas de aprovechamiento privado sobre los espacios públicos. Estas iniciativas encuentran gran acogida entre las municipalidades urbanas que, en busca de nuevas fuentes de ingreso, intervienen sobre los espacios públicos con este tipo de iniciativas privadas, desnaturalizando el concepto de «lo público».

El aprovechamiento privado del espacio público (subsuelo, superficie y aires) supone que la administración pública promueva el desarrollo de una iniciativa privada para «optimizar» el uso del suelo, generando nuevos espacios comerciales y de disfrute para la ciudadanía. Esta lógica ha provocado la apropiación de un nuevo marco legal de rango nacional por proyectistas privados y municipalidades distritales. Bajo esta premisa, se otorga un valor al espacio público de acuerdo con la expectativa de rentabilidad financiera que pueda generar (valor de cambio). Por el contrario, se deja de lado todo tipo de valorización relacionada con los servicios ambientales, culturales, deportivos y de recreación que puedan tener los espacios públicos (valor de uso).

El objetivo de este artículo es evidenciar cómo la regulación pública y las lógicas del capital privado que ocurren sobre los espacios públicos de la ciudad de Lima influyen en las medidas que están adoptando los gobiernos locales y movimientos ciudadanos. 
El artículo se centra en el análisis de dos iniciativas privadas que pretendían desarrollarse en espacios públicos de Lima Norte: el parque Manhattan en el distrito de Comas y la Alameda Los Incas en el distrito de Independencia. Ambas iniciativas tenían como fin desarrollar infraestructura comercial sobre espacios públicos municipales. Asimismo, ambos casos derivaron en la movilización de vecinos que lograron frenar los planes de privatización del espacio.

El artículo recoge información de fuentes secundarias sobre los dos casos, principalmente de medios escritos, y en el caso del Parque Manhattan también se recoge información de conversaciones que se tuvieron con la organización vecinal que lideró la defensa. El artículo se divide en cinco partes. La primera parte presenta los casos, caracterizando la problemática y los elementos que la componen. En la segunda parte analizaremos el ordenamiento jurídico que rige sobre los espacios públicos y, en la tercera, la participación de las iniciativas privadas, donde evidenciamos cómo se articula el arreglo de toma de decisiones y qué asimetrías de poder existen entre quienes participan del mismo. La cuarta parte analiza el rol de los movimientos vecinales en defensa de los espacios públicos. Finalmente, la quinta parte presenta reflexiones para la ciudad a partir del análisis de las iniciativas privadas en espacios públicos. 


\section{Los casos: el Parque Manhattan y la Alameda Los Incas}

Los casos de defensa del Parque Manhattan y Alameda Los Incas se encuentran en los distritos de Independencia y Comas, ubicados en parte norte de la ciudad de Lima, más conocida como Lima Norte ${ }^{3}$. Estos distritos forman parte de la llamada «ciudad popular», nombre por el que se conoce a los distritos que formaron parte del periodo clásico de expansión urbana que duró hasta fines de los años 80 (Barreda y Ramírez Corzo 2004).

En los últimos 30 años, la estructura urbana de Lima Metropolitana ha dejado de estar organizada en torno a un solo centro y ha pasado a formar una ciudad policéntrica, aunque con distintos niveles de consolidación (Gonzales De Olarte y Del Pozo 2012). Lima Norte ha formado algunos núcleos económicos que la han ido convirtiendo en un mercado atractivo para la inversión privada. Según la Memoria del Plan Metropolitano de Desarrollo Urbano de Lima y Callao 2035 (2014), Lima Norte concentra el 20.59\% de establecimientos laborales y $10.28 \%$ del total de empleos de Lima y Callao ${ }^{4}$. La mayor cantidad de empleos se agrupan en 4 distritos: San Martín de Porres, Los Olivos, Comas e Independencia. Existe una alta concentración de empleos en la zona colindante a grandes ejes viales como las avenidas Túpac Amaru, Panamericana Norte (zona se ubican los centros comerciales Plaza Lima Norte, Royal Plaza y MegaPlaza, entre otras grandes tiendas, y el servicio de transporte del Metropolitano), Universitaria, Canta Callao, Tomás Valle y Carlos Izaguirre.

Además de ser policéntrica, Lima y Callao son heterogéneos en su composición social. El proceso urbano de Lima y Callao nos muestra que la metrópoli modifica constantemente su estructura segregativa. De acuerdo a nuevos enfoques sobre el tema de segregación urbana, sabemos que en la actualidad el concepto tradicional de espacios segregados periféricos y

\footnotetext{
${ }^{3}$ Lima Norte está conformada por los distritos de Ancón, Carabayllo, Comas, Independencia, Los Olivos, Puente Piedra, San Martín de Porres y Santa Rosa.

4 Información elaborada por la Memoria del PLAM 2035 (2014) en base al Censo Económico de 2008.
} 
homogéneos no se condice con las complejidades que supone el grado de concentración poblacional y distribución espacial actual de la ciudad (Fernández de Córdova 2012). En el caso de la «ciudad popular» y los distritos de Lima Norte que la componen, observamos distintos niveles de consolidación y marginalidad. Son los espacios más consolidados los que alojan estos nuevos centros económicos. Esto no excluye que en los distritos subsistan espacios marginados con las características típicas de la segregación urbana.

El Parque Manhattan se ubica en la Urbanización San Felipe, zona consolidada del distrito de Comas colindante a la avenida Universitaria. El proyecto Nuevo Manhattan ${ }^{5}$ se propuso en febrero de 2015 y consistía en la construcción de un centro comercial que incluía un supermercado, cines, patio de comidas y estacionamientos sobre el área que actualmente ocupan dos losas deportivas y parte de la pista atlética del Parque Manhattan. La constructora Urbi Propiedades S.A., del grupo Intercorp, propuso al municipio de Comas la suscripción de un contrato de constitución de derecho de superficie para la ejecución del proyecto de inversión privada por un plazo de 40 años, amparado en el Decreto Legislativo $N^{\circ} 1224$ (antes D.L. $N^{\circ} 1012$ ) del marco de promoción de la inversión privada mediante asociaciones público-privadas y proyectos en activos, bajo la modalidad de proyectos en activos.

${ }^{5}$ Información pública a través de comunicados de prensa y Acuerdo de Concejo N 055-2016-MDC. 
De acuerdo con la propuesta, la empresa se comprometía a hacer un pago adelantado por el derecho de superficie de 1.6 millones de dólares y un pago de 832,430 dólares para obras de rehabilitación y mejoramiento del Parque que serían depositados en un fideicomiso, y el pago mensual de alquiler de 5,500 dólares por el plazo de vigencia del contrato (fuera del fideicomiso). Al término del contrato, las construcciones sobre el área comercial se transferirían a título gratuito a favor de la Municipalidad distrital. En suma, el proyecto de inversión ascendía aproximadamente a 17.3 millones de dólares, incluido IGV.

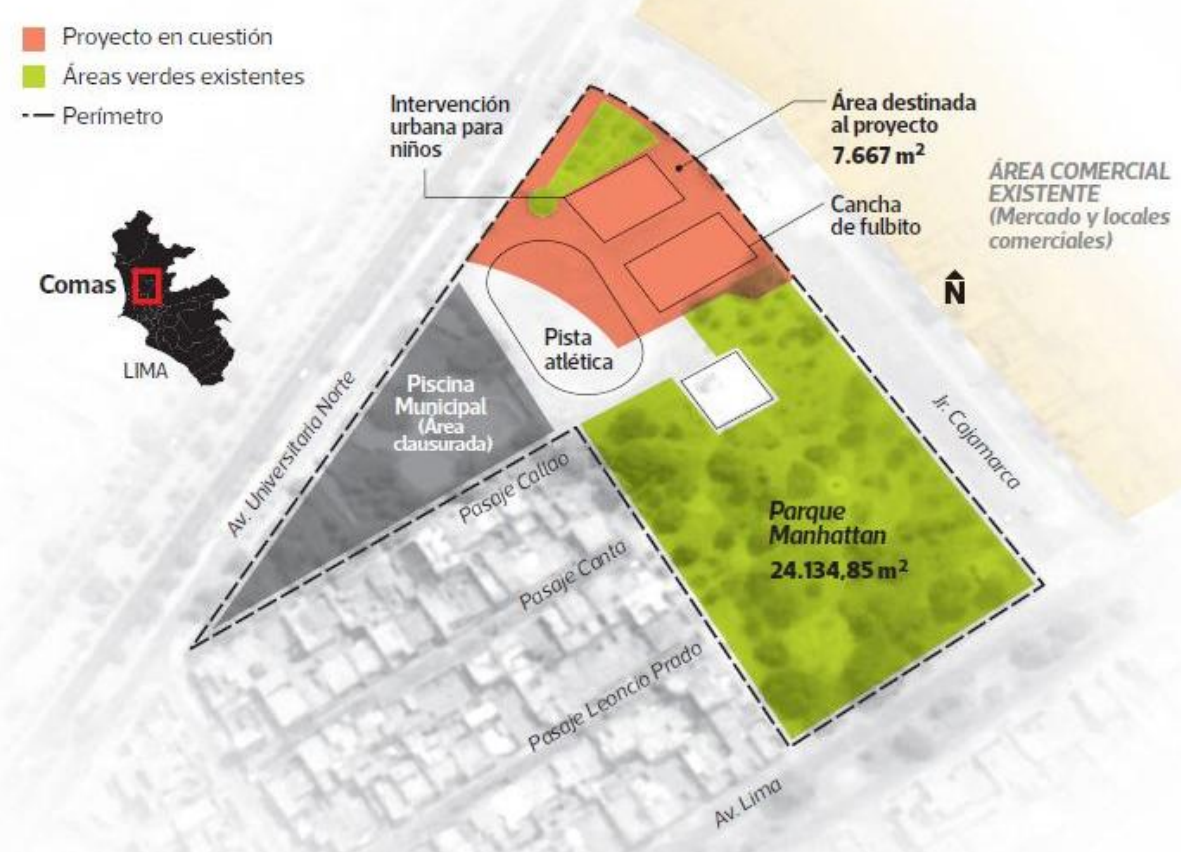

Imagen 1. Mapa del Parque Manhattan y la iniciativa privada. Fuente: El Comercio del 09 de noviembre de 2016. Comas quiere convertir área de parque en centro comercial ${ }^{6}$.

\footnotetext{
${ }^{6}$ Ver en Comas quiere convertir área de parque en centro comercial https://elcomercio.pe/lima/comas-quiereconvertir-area-parque-centro-comercial-147407 del 09 de noviembre de 2016.
} 
El 02 de setiembre de 2016, por medio del Acuerdo de Concejo Municipal $\mathrm{N}^{\circ}$ 055-2016-MDC, la Municipalidad de Comas declaró el interés por la iniciativa. Inmediatamente, la Municipalidad empezó una campaña de promoción del proyecto, para convencer a los vecinos de los beneficios económicos que traería para la Urbanización San Felipe y alrededores ${ }^{7}$. Vale la pena señalar que las imágenes utilizadas del parque, donde se ve abandonado, no correspondían a la realidad, como denunciaron los vecinos en su momento.
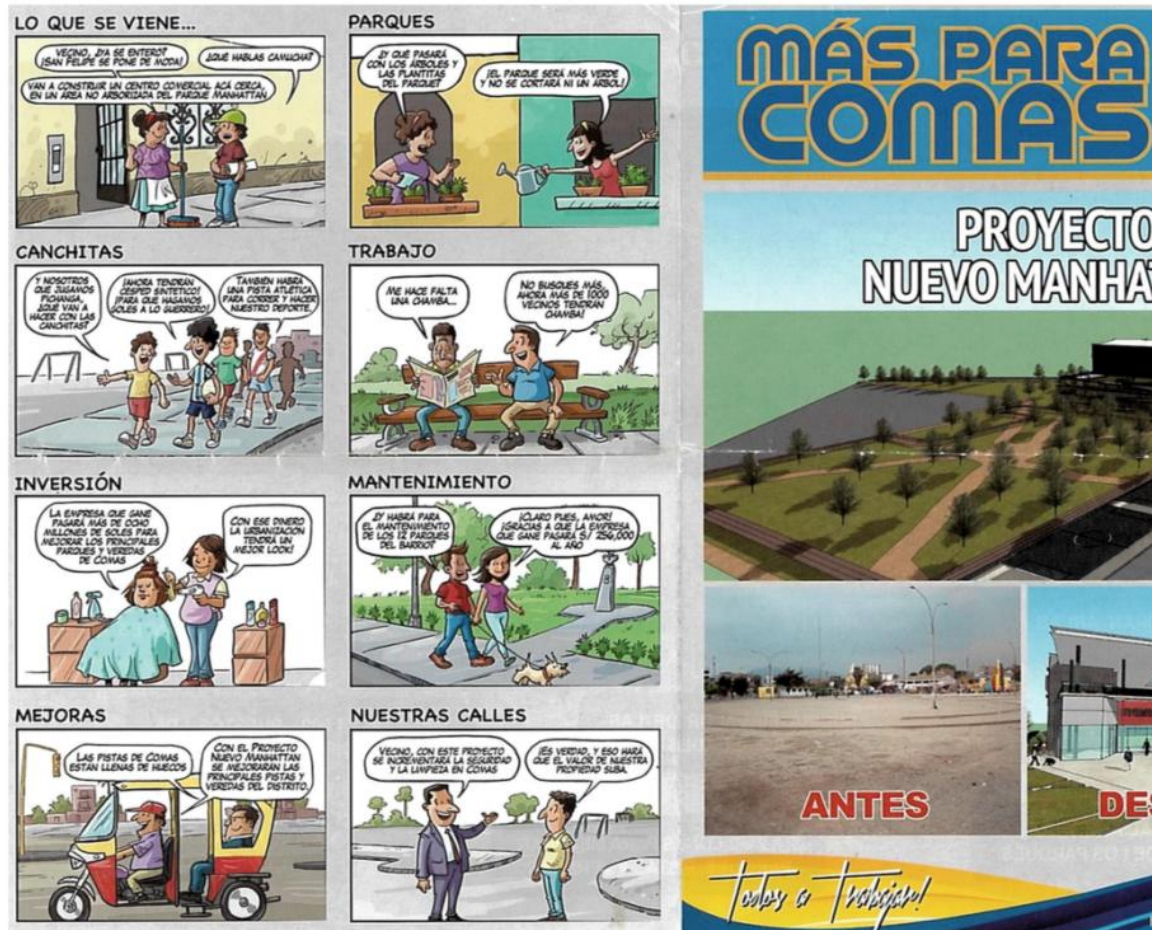

PRovisto NUEVO MANTIATIAN
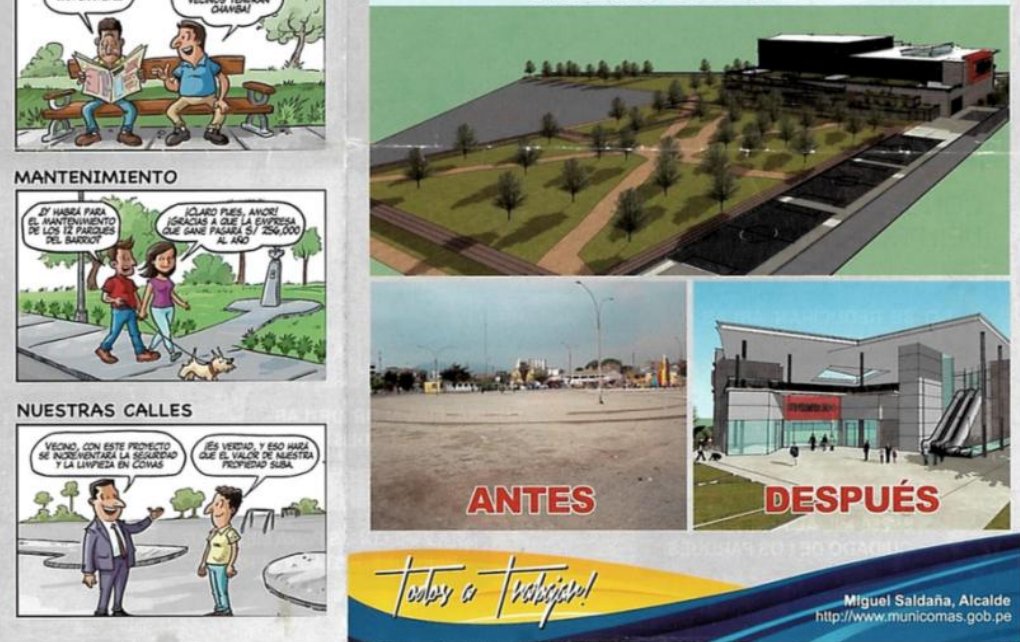

Imagen 2. Campaña de promoción de la Municipalidad de Comas para iniciativa privada. Fuente: Imagen tomada del material distribuido a vecinos y vecinas.

7 Ver en Comas espera la llegada de sus primeros dos centros comerciales https://gestion.pe/economia/empresas/comas-espera-llegada-primeros-dos-centros-comerciales-114867 del 09 de setiembre de 2016 
El alcalde de Comas llegó a declarar a un medio escrito ${ }^{8}$ que el Parque no era «rentable» tal como estaba. Por su parte, la empresa proponente de la iniciativa privada se dedicó a promocionar el proyecto en diversos diarios de circulación nacional en la sección de «Empresas».

Respecto a la naturaleza del bien donde se encuentra el Parque, el Acuerdo de Concejo Municipal $\mathrm{N}^{\circ}$ 055-2016-MC mencionaba necesario que la Municipalidad distrital regularice la inscripción del bien en Registros Públicos a su nombre. Así también, la Municipalidad debía gestionar la subdivisión, desafectación y cambio de zonificación del área sobre el cual se pretendía desarrollar la iniciativa privada luego de suscrito el contrato de superficie. Cabe señalar que la empresa proponente tenía conocimiento del área que iba a afectar y lo justificaba de la siguiente manera:

El área propuesta para ejecutar el Proyecto actualmente se encuentra utilizada como parte del parque y como áreas deportivas, sin embargo, estas se encuentran en mal estado. Este uso de suelo es ineficiente y por ello proponemos un proyecto que permita que se promueva infraestructura de buena calidad, que se encuentre en buen estado y que a su vez permita generar ingresos para mantener dicho activo y consolidar así el Parque Manhattan. (Iniciativa Privada Proyecto "Parque Manhattan" presentada por Supermercados Peruanos S.A. representado por Urbi Propiedades S.A. Diciembre de 2015. pp. 23)

8 Ver en Parque de Comas se convertirá en supermercado al no ser 'rentable' https://larepublica.pe/sociedad/1019166-parque-de-comas-se-convertira-en-supermercado-al-no-ser-rentable del 27 de febrero de 2017. 

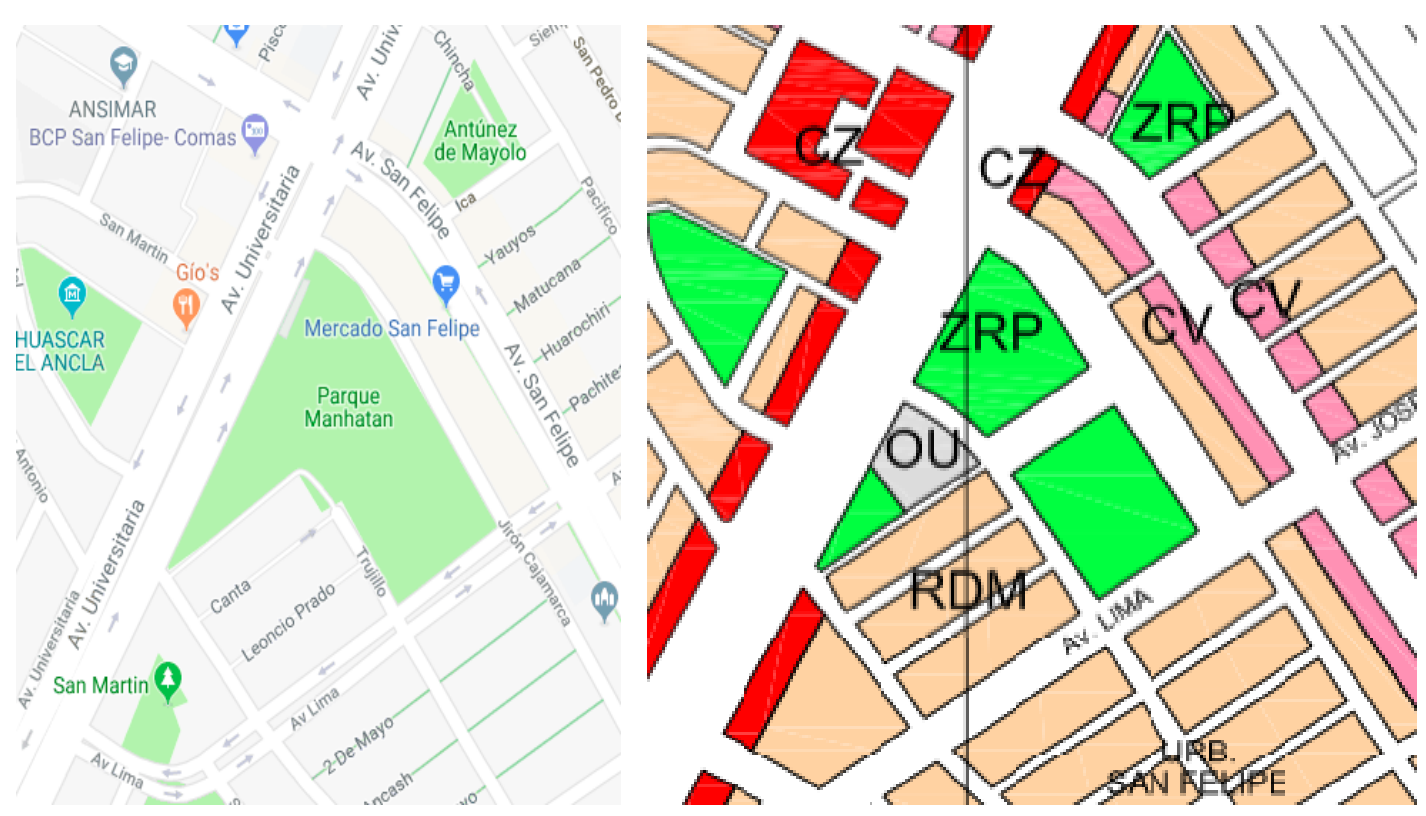

Imagen 3. Mapa de ubicación y zonificación de Parque Manhattan en el distrito de Comas. Fuente: Google Maps $\mathrm{y}$ http://eudora.vivienda.gob.pe/OBSERVATORIO/ZONIFICACION/Comas.pdf

Tras una sostenida defensa de los vecinos del Parque como una zona de recreación pública, se decidió dejar sin efecto el Acuerdo de Concejo $\mathrm{N}^{\circ} 055$ 2016-MC que declaraba de interés la iniciativa privada del Parque Manhattan mediante Acuerdo de Concejo $\mathrm{N}^{\circ}$ 006-2018-MC del 14 febrero de 2018.

La Alameda Los Incas se encuentra en la Urbanización Tahuantinsuyo, colindante a la avenida Túpac Amaru y en una zona consolidada del distrito de Independencia. Aquí el Grupo LAR Desarrollos Inmobiliarios SAC y 3BL SAC propuso, en julio del 2015, la iniciativa privada New Life Independencia, también en el marco legal de promoción de la inversión privada mediante asociaciones público-privadas y proyectos en activos. El proyecto de inversión ascendía a aproximadamente 27.5 millones de dólares y consistía en la construcción de 7 torres de vivienda con áreas comerciales en los primeros pisos sobre el área más amplia de la alameda, como se puede 
apreciar en la siguiente Ilustración. Además, un coliseo deportivo, casetas de seguridad y un skate park.
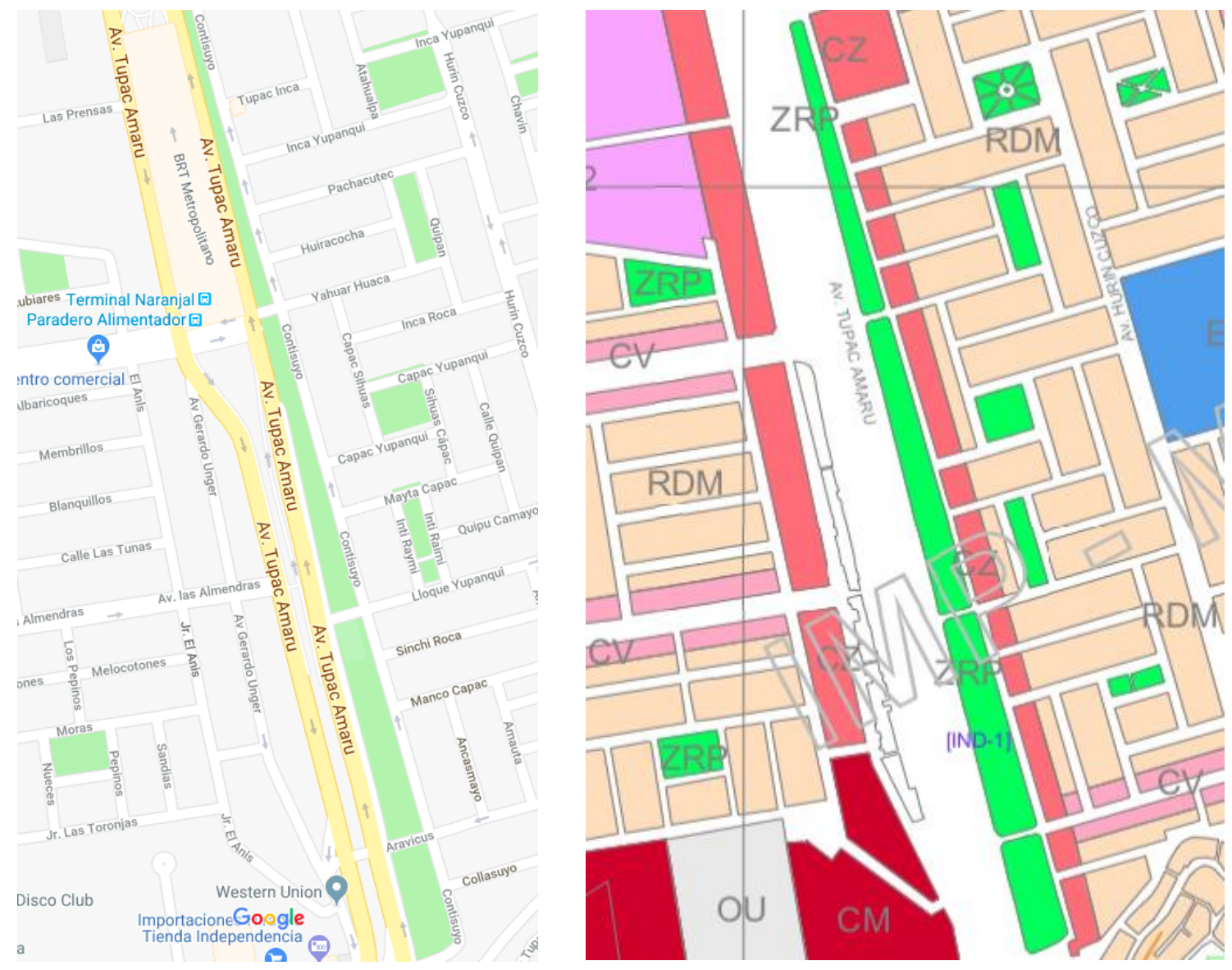

Imagen 4. Mapa de ubicación y zonificación de Alameda Los Incas en el distrito de Independencia. Fuente: Google Maps $\mathrm{y}$ http://www.muniindependencia.gob.pe/data files/funcionamiento/PLANO\%20DE\%20ZONI FICACION.pdf

Al igual que en el caso del Parque Manhattan, la Municipalidad de Independencia realizó una campaña de promoción de la iniciativa privada aludiendo a la modernidad y el progreso. A diferencia del caso Manhattan, la modalidad de inversión propuesta por la empresa fue una asociación público- 
privada en la alameda. No se precisaba, en este sentido, qué pasaría con la titularidad del área que ocuparían las siete torres de vivienda. Por su parte, la empresa proponente de la iniciativa privada difundió videos para promocionar el proyecto. La iniciativa obtuvo todos los informes técnicos favorables de las gerencias competentes de la Municipalidad distrital, como quedaron registrados en el Acuerdo de Concejo No 049-2016-MDI, del 28 de setiembre de 2016. Sin embargo, este Acuerdo optó por no declarar de interés la iniciativa privada, debido a la movilización de rechazo de los vecinos y organizaciones locales de sociedad civil a cambiar el uso de recreación pública de la Alameda por un uso comercial.

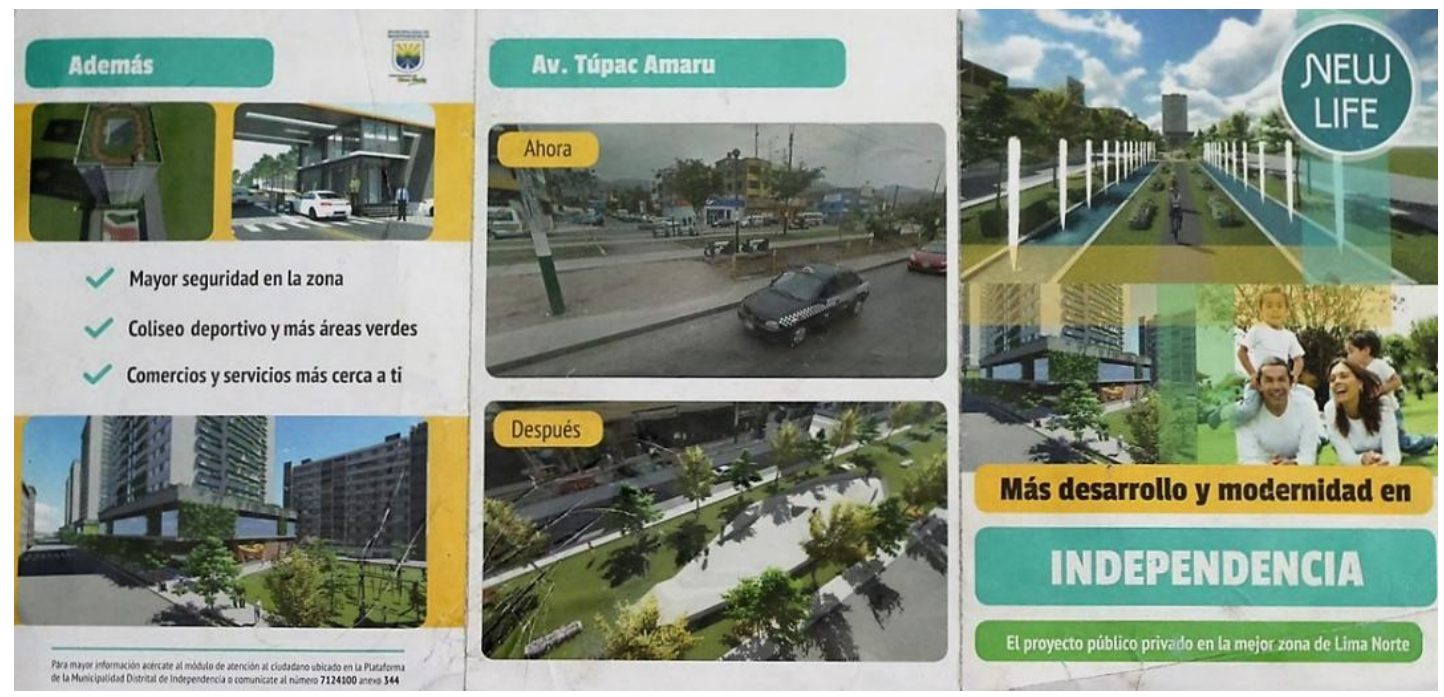




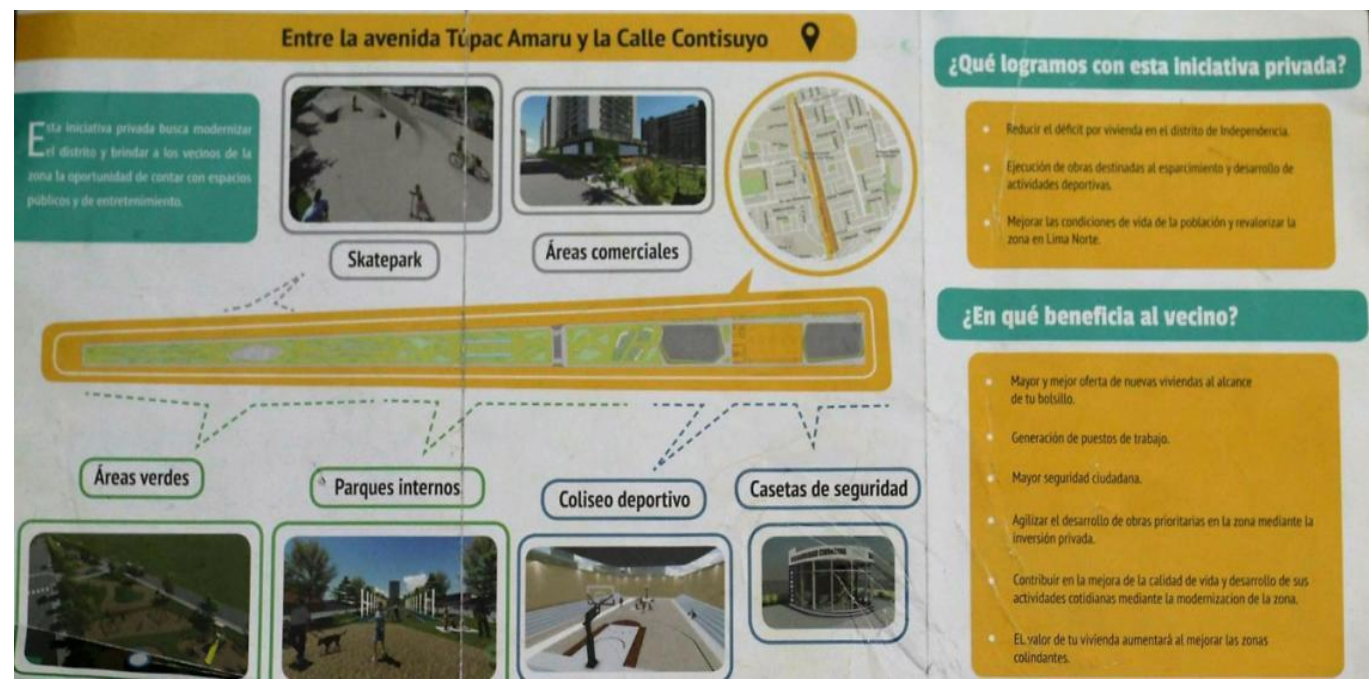

Imágenes 5 y 6. Campaña de promoción de la Municipalidad de Independencia para iniciativa privada. Fuente: $\mathrm{Blog} \mathrm{De} \mathrm{A} \mathrm{Pie}^{9}$ New Life Independencia: cuando el lobo se disfraza de oveja.

Ambos casos comparten ciertas características:

- El Parque Manhattan y la Alameda Los Incas se ubican en zonas que pasaron por un proceso de habilitación urbana por lo que son parte de los aportes reglamentarios. Ambos espacios se encuentran calificados en el plano de zonificación como Zona de Recreación Pública.

- Ambos casos están localizados en zonas en las que el suelo tiene un alto valor por ser colindantes a avenidas importantes de Lima Norte, la Alameda es a la Av. Túpac Amaru y el Parque a la Av. Universitaria. Además, la Alameda se encuentra frente a la estación Naranjal del Metropolitano en Independencia y la próxima ampliación de la línea del Metropolitano en Comas pasará frente al Parque.

9 Ver New Life Independencia: cuando el lobo se disfraza de oveja http://deapie.utero.pe/2016/06/28/new-lifeindependencia-cuando-el-lobo-se-disfraza-de-oveja/ del 28 de junio de 2016. 
- Las iniciativas privadas fueron presentadas a las municipalidades por empresas multinacionales en el marco legal de la promoción de la inversión privada.

- Las municipalidades distritales de Comas e Independencia asumen la promoción pública de las iniciativas privadas a través de volantes, declaraciones en audiencias vecinales y medios de comunicación, a pesar de que dichas iniciativas suponían un uso comercial, un uso no conforme con la zonificación y normatividad vigente de las áreas donde se desarrollarían.

- Las municipalidades distritales de Comas e Independencia hacen referencia en comunicados a la opinión pública sobre el poco presupuesto con el que cuentan para realizar el mantenimiento de áreas verdes. Razón que es utilizada para justificar la conveniencia de las iniciativas privadas.

- Ambas iniciativas privadas fueron desestimadas o archivadas por Acuerdo de Concejo debido a las movilizaciones que realizaron los vecinos y organizaciones locales de sociedad civil en contra del cambio de uso de sus espacios públicos.

Los casos evidencian que, cuando el valor del suelo es alto y las municipalidades tienen presupuestos limitados, la conservación de áreas planificadas para uso de recreación pública entra en competencia con el nuevo proyecto comercial que ofrece una rentabilidad financiera. Los casos evidencian conflictos que se generan entre quienes defienden el valor de uso (vecinos) y quienes defienden el valor de cambio (municipalidad y empresa). Además, se evidencia que el discurso adoptado por las municipalidades se basa en el marco legal de promoción de la inversión privada y obvia el marco legal para la conservación de espacios públicos verdes.

Por un lado, en cuanto al uso del marco legal de la promoción de la inversión privada por las municipalidades, se observa un sesgo al valorar el uso actual que tienen los bienes públicos sobre los que se desarrollarían las iniciativas. 
Un ejemplo de este sesgo es que actualmente no existe un mecanismo aprobado por el Estado que permita valorar los beneficios económicos de un parque, y con ello, la posibilidad de compararlos frente a los beneficios económicos de un centro comercial.

Por otro lado, se podría pensar que el marco legal de conservación de espacios públicos no es lo suficientemente claro o completo. Sin embargo, como se muestra a continuación, el problema se debe principalmente a la falta de control y fiscalización a las decisiones tomadas por las municipalidades, pero también a que la normativa no está tomando en consideración las dinámicas del mercado del suelo, como los incentivos económicos que existen para generar cambios de zonificación a usos más rentables.

\section{Los espacios públicos entendidos a través de las leyes}

El Perú no cuenta con una ley general de desarrollo urbano ni con un código urbano. En consecuencia, las normas que rigen para los espacios públicos están dispersas y esto dificulta su defensa. Lo que existe son múltiples leyes, decretos reglamentarios y normas de nivel provincial y distrital aplicables en Lima, que regulan - por separado y con distintos grados de profundidadalgunos de los elementos del espacio público verde.

\begin{tabular}{|l|l|l|r|}
\hline \multirow{4}{*}{ Nivel nacional } & - & Constitución Política del Perú. & \\
& Ley $\mathrm{N}^{\circ}$ 27972, Ley Orgánica de \\
& Municipalidades (LOM), que regula las \\
& competencias de las municipalidades en \\
& materia urbanística. & \\
- & Ley $\mathrm{N}^{\circ}$ 29090, Ley de Regulación de \\
& Habilitaciones Urbanas y de Edificaciones y su \\
& reglamento que regula la competencia y los \\
& procesos de aprobación de las licencias de \\
& habilitación urbana y edificación. \\
\hline
\end{tabular}




\begin{tabular}{|c|c|}
\hline & 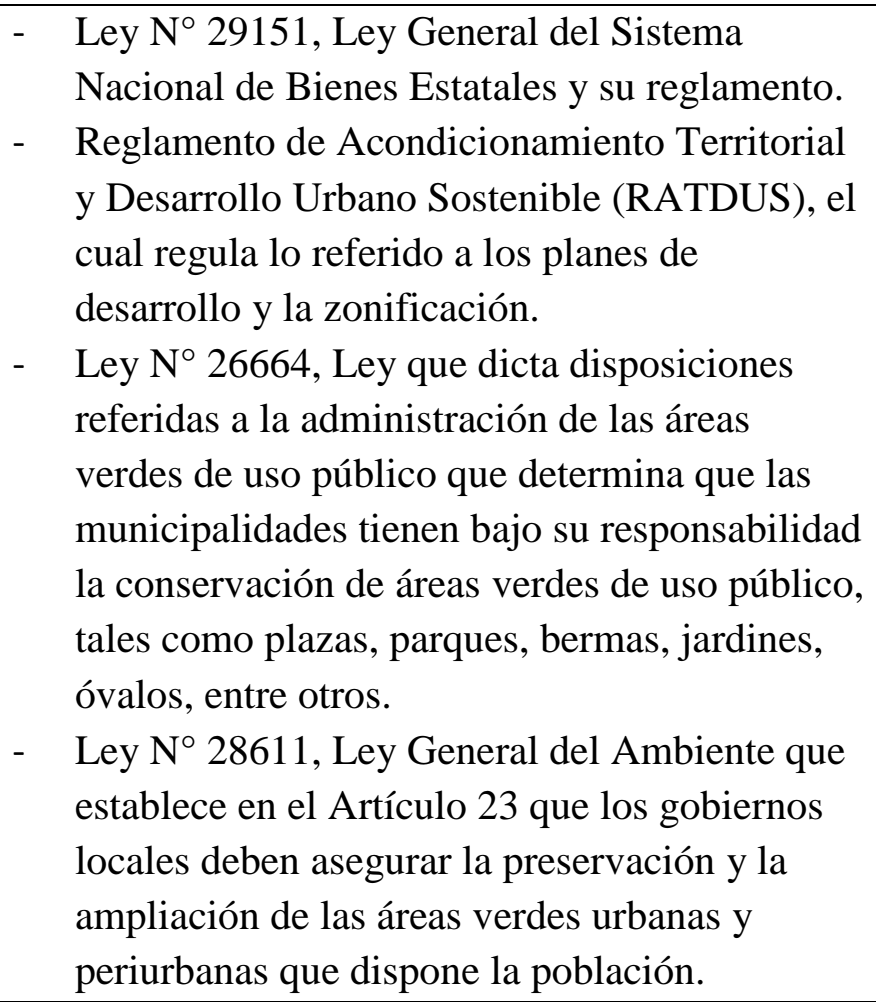 \\
\hline Nivel local & 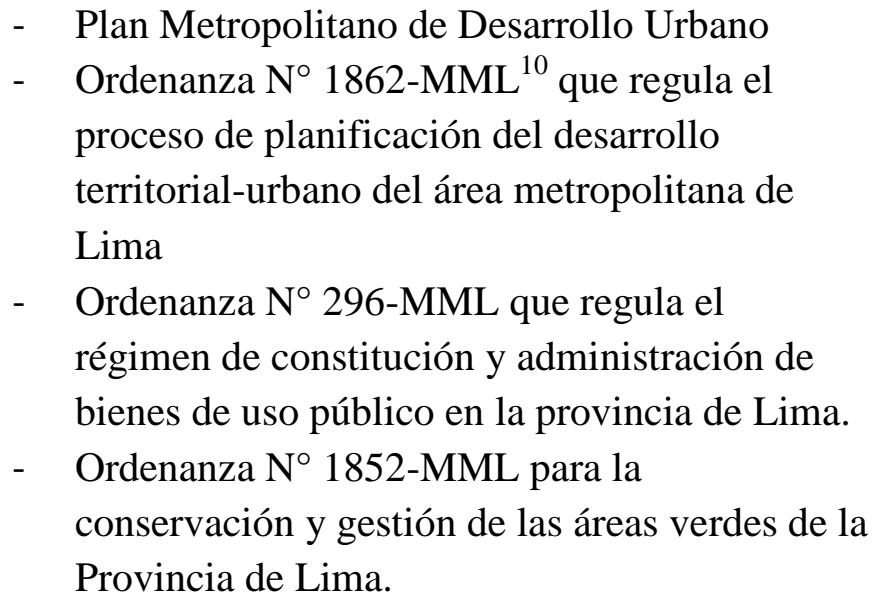 \\
\hline
\end{tabular}

Cuadro 1. Normas de nivel nacional y local que guardan relación directa con los espacios públicos

10 Deroga la Ordenanza 620-MML reglamentaria del proceso de aprobación del Plan Metropolitano de Acondicionamiento Territorial y Desarrollo Urbano de Lima, de planes urbanos distritales y actualización de la zonificación de los usos del suelo de Lima Metropolitana. 
Para efecto del análisis de los casos, nos concentraremos solo en algunas de las normas.

La creación de áreas de recreación pública, como son los espacios públicos verdes, se da a través de los aportes requeridos en un proceso de habilitación urbana, proceso de convertir un terreno rústico o eriazo en urbano. La Ley $\mathrm{N}^{\circ}$ 29090, Ley de Regulación de Habilitaciones Urbanas y de Edificaciones, establece en su Artículo 3 como parte de la definición de Habilitación Urbana $^{11}$ que estos aportes son áreas de uso público irrestricto y constituyen bienes de dominio público:

Este proceso requiere de aportes gratuitos y obligatorios para fines de recreación pública, que son áreas de uso público irrestricto; así como para servicios públicos complementarios, para educación, salud y otros fines, en lotes regulares edificables que constituyen bienes de dominio público del Estado, susceptibles de inscripción en el Registro de Predios de la Superintendencia Nacional de los Registros Públicos. (Art. 3 Ley N 29090, Ley de Regulación de Habilitaciones Urbanas)

Según la Ley $\mathrm{N}^{\circ}$ 29151, en sus artículos 8 y 9 establece que los gobiernos locales conforman el Sistema Nacional de Bienes Estatales y los actos que realizan los gobiernos locales, respecto de los bienes de su propiedad, así como los de dominio público que se encuentran bajo su administración, se ejecutan conforme a la Ley $N^{o}$ 27972, Ley Orgánica de Municipalidades, y a la presente Ley y su reglamento, en lo que fuera aplicable, estando obligados a remitir a la SBN información de los referidos bienes para su registro en el Sistema de Información Nacional de Bienes Estatales - SINABIP. Además, en el caso de bienes de dominio público bajo administración local, la SBN deberá efectuar las funciones de supervisión y registro. El Reglamento de la Ley $\mathrm{N}^{\circ}$ 29151, aprobado por el D.S. 007-2008-VIVIENDA, define en el

\footnotetext{
11 El Decreto Supremo Nº06-2017-VIVIENDA que aprueba el Texto único Ordenando de la Ley $\mathrm{N}^{\circ} 29090$, considera los siguientes procedimientos de Habilitación Urbana: Habilitación Urbana Nueva, Habilitación Urbana Nueva y Reurbanización.
} 
Artículo 2 como bienes de uso y dominio público a parques, plazas, aportes reglamentarios, entre otros.

Según el Artículo 56 de la LOM, los aportes provenientes de habilitaciones urbanas son considerados bienes de propiedad municipal. Por lo que se desprende que la administración de los espacios públicos verdes está a cargo de las municipalidades.

El Artículo 195 de la Constitución entrega la función pública del urbanismo a las municipalidades. Esta función implica que las municipalidades tienen la competencia de aprobar la planificación del desarrollo urbano, la zonificación y el acondicionamiento territorial de sus jurisdicciones. Esta función para que desarrollen, ordenen y mantengan adecuadamente el uso del suelo y de los espacios se encuentra desarrollada principalmente en la Ley $\mathrm{N}^{\circ}$ 27972, Ley Orgánica de Municipalidades (LOM) (Ortiz, 2017).

La zonificación urbana de los dos casos de espacios públicos, el parque y la alameda, aparecen como Zonas de Recreación Pública (ZRP). El Reglamento de Acondicionamiento Territorial y Desarrollo Urbano Sostenible (RATDUS) define a las ZRP como "áreas que se encuentran en zonas urbanas o urbanizables destinadas fundamentalmente a la realización de actividades recreativas activas y/o pasivas como: plazas, parques, juegos infantiles y similares". Al gobierno provincial, en este caso la Municipalidad Metropolitana de Lima, le compete regular mediante ordenanza la zonificación de la ciudad (Ordenanza N 1862-MML y modificatorias).

La zonificación puede definirse como el instrumento técnico-normativo del plan de desarrollo urbano que identifica el uso del suelo urbano y divide una ciudad en zonas de uso ${ }^{12}$. Otra importante característica de la zonificación es que es un instrumento político, debido a que a) el Concejo Municipal (un

\footnotetext{
12 Según el avance del PLAM 2035 (2014), las modificaciones en los planos de zonificación de la metrópoli LimaCallao se han dado principalmente en base a la ocupación existente y no por la orientación que se promovió mediante la zonificación general establecida en el plan metropolitano 1990-2010, lo que ha derivado en la pérdida importantes áreas con funciones de preservación.
} 
cuerpo político) debe aprobar los usos de suelo; b) el proceso debe incluir una consulta vecinal para su regulación; y, c) existe un alto grado de influencia política sobre las decisiones tomadas (Ortiz, 2017).

Finalmente, es importante señalar la Ordenanza $\mathrm{N}^{\circ} 1852$ para la conservación y gestión de las áreas verdes de la Provincia de Lima. La relevancia de esta ordenanza para el análisis de los casos del Parque Manhattan y la Alameda Los Incas se puede enfocar en los siguientes aspectos: la ordenanza define como áreas verdes de uso público a las áreas o espacios verdes de dominio y uso público ubicados en los parques, plazas, alamedas, aportes, entre otros; establece que el área verde está comprendida por el subsuelo, superficie y aires; establece que la Municipalidad Metropolitana de Lima y las Municipalidades Distritales están obligadas a conservar, defender, proteger y mantener las áreas verdes de uso público bajo su jurisdicción; entre las medidas de protección, no permite desarrollo de obras de infraestructura que sean ajenas a las finalidades de recreación activa o pasiva, y establece que cualquier afectación a la zonificación o régimen de uso de las áreas verdes públicas deberá contar con la opinión ambiental favorable de la Gerencia del Ambiente; las Municipalidades promoverán la participación ciudadana en la gestión y manejo sostenible de las áreas verdes, y en caso de controversias se deberán crear espacios de diálogo con las organizaciones vecinales representativas del área de influencia, con la participación de los colegios profesionales relacionados.

En resumen, estas son las normas de nivel nacional y local que debieron haber protegido al Parque Manhattan y la Alameda Los Incas. Sin embargo, los casos muestran que la ley de las iniciativas privadas pesa más en el actual arreglo de toma de decisiones. Además, las municipalidades distritales de Comas e Independencia no tuvieron ningún impedimento legal para declarar de interés (en el primer caso) y emitir informes favorables (segundo caso) sobre las iniciativas privadas que pretendían construir centros comerciales sobre estos espacios públicos. 
En el caso del Parque Manhattan, la iniciativa proponía el cambio de zonificación del parque como parte de las autorizaciones que permitirían poner en uso «más eficiente» el activo (parque), obviando o relegando a un segundo plano la decisión de la ciudad de darle un uso de recreación pública, decisión que se encuentra materializada en la ordenanza que aprueba la zonificación. Es así que la defensa de los dos espacios públicos verdes se da por el control social de los vecinos y vecinas y no por el cumplimiento de las normas por parte de las instituciones competentes.

La revisión de las normas anteriormente mencionadas dan cuenta, y como se señaló anteriormente, que no se está tomando en consideración las dinámicas del mercado del suelo. El marco jurídico podría funcionar mejor para la conservación de áreas de recreación pública si tomara en consideración los incentivos económicos que existen para generar cambios de zonificación a usos más rentables. Para ello, también sería importante que el marco jurídico se adapte al proceso urbano actual. La normativa estuvo pensada para una ciudad en expansión. Hoy tenemos un uso mucho más intensivo del suelo disponible y los procesos de densificación por los que atraviesan ciudades como Lima, con casos como los vistos, evidencian el surgimiento de conflictos que podrían volverse cada vez más comunes.

\section{La promoción de la inversión privada y su rol en el desarrollo de la ciudad}

Las iniciativas privadas para grandes proyectos de infraestructura, inmobiliarios y comerciales se han convertido en un nuevo gran actor en el desarrollo de la ciudad en Lima. Ello tiene sus orígenes en las reformas estructurales de la década de los noventa que, como en otros países de la región, tuvieron por objetivo definir un nuevo marco institucional para la economía peruana. Bajo la actual Constitución, el mercado se configura como el principal asignador de recursos y el Estado asume el papel de 
regulador (Parodi 2005). Estas reformas llevaron al debilitamiento del rol planificador del Estado en todos sus niveles. Un ejemplo muy concreto fue el Plan de Desarrollo Metropolitano Lima-Callao 1990-2010, que anunciaba la erradicación del concepto restrictivo y controlista del Estado por un enfoque promotor o de incentivos a las iniciativas particulares (Stiglich 2012). La lógica de este modelo sugiere que la inversión privada sea el motor del crecimiento y para ello el Gobierno Central ha promulgado diversas leyes que la promueven y que se han ido sofisticando con el tiempo.

\begin{tabular}{|c|c|}
\hline Nivel nacional & 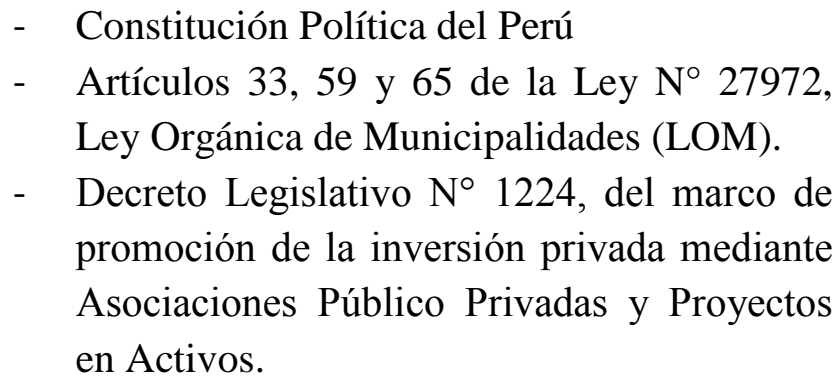 \\
\hline Nivel local & $\begin{array}{l}\text { - Ordenanza } \mathrm{N}^{\circ} \text { 2046-MML, disposiciones } \\
\text { para la aplicación del marco de promoción } \\
\text { de la inversión privada mediante } \\
\text { asociaciones público privadas y proyectos en } \\
\text { activos en Lima Metropolitana. }\end{array}$ \\
\hline
\end{tabular}

Cuadro 2. Normas de nivel nacional y local que guardan relación directa con las iniciativas privadas

La Ley Orgánica de Municipalidades (LOM) establece que las municipalidades deben promover el desarrollo económico y social, siendo unos de los canales el fomento de la inversión privada. Según el Artículo 33 
de esta Ley, las municipalidades pueden otorgar concesiones a personas jurídicas, nacionales o extranjeras, para la ejecución y explotación de obras de infraestructura o de servicios públicos locales. Por otro lado, el Artículo 59 establece que los bienes municipales pueden ser transferidos, concesionados en uso o explotación, arrendados o modificar su estado de posesión o propiedad, por acuerdo del Concejo Municipal. En cuanto a la cesión en uso o concesión, el Artículo 65 de la LOM establece lo siguiente:

Las municipalidades están facultadas para ceder en uso o conceder en explotación bienes de su propiedad, en favor de personas jurídicas del sector privado, a condición de que sean destinados exclusivamente a la realización de obras o servicios de interés o necesidad social, y fijando un plazo. (Art. 65 Ley Orgánica de Municipalidades)

Como se mencionó anteriormente, la administración de los espacios públicos verdes está a cargo de las municipalidades y la LOM permite su concesión o cesión en uso. Sin embargo, esta cesión entra en conflicto con el uso de recreación pública que tienen los espacios. Las iniciativas privadas del Parque Manhattan y la Alameda Los Incas pretendían desarrollar infraestructura para uso comercial, restringiendo otras libertades que las personas ejercen en el espacio público.

Puede inferirse que la interpretación de la LOM que hacen las municipalidades al momento de admitir iniciativas privadas en los espacios públicos se basa en el Artículo 73 de la Constitución Política del Perú. El artículo 73 establece que «los bienes de dominio público son inalienables e imprescriptibles»y «pueden ser concedidos a particulares conforme a ley, para su aprovechamiento económico». Al respecto, y aunque es poco conocida, el Tribunal Constitucional emitió una sentencia ${ }^{13}$ en el año 2004

\footnotetext{
${ }^{13}$ La sentencia del Tribunal Constitucional que acumula los expedientes EXP. № 015-2001-Al/TC, EXP. № 0162001-Al/TC, EXP. N ${ }^{\circ}$ 004-2002-Al/TC, precisa en el fundamento 29, que los bienes de dominio público están destinados a la satisfacción de intereses y finalidades públicas. Demandas de inconstitucionalidad interpuestas por el Colegio de Abogados de Ica y la Defensoría del Pueblo contra el Decreto de Urgencia N. ${ }^{\circ}$ 055-2001, y demanda de inconstitucionalidad interpuesta por el Colegio de Abogados de Ica contra la Ley N. ${ }^{\circ} 27684$.
} 
que interpreta este artículo a favor de la defensa del uso público de parques y alamedas:

El dominio público es una forma de propiedad especial, afectada al uso de todos, a un servicio a la comunidad o al interés nacional, es decir, que está destinada a la satisfacción de intereses y finalidades públicas y, por ello, como expresa el artículo $73^{\circ}$ de la Constitución, tiene las características de bienes inalienables e imprescriptibles, además de inembargables. (Tribunal Constitucional 2004)

Es importante resaltar la sentencia del Tribunal Constitucional, ya que en los casos del Parque Manhattan y Alameda Los Incas se pretendía construir centros comerciales, que son iniciativas destinadas a la satisfacción de intereses privados, no públicos.

Otro aspecto por considerar es la manera en cómo se administran las cuentas municipales a partir del proceso de descentralización que inició el Perú inició en el año 2002. Actualmente la mayor parte de las funciones de los gobiernos locales se financian a través de las transferencias del gobierno nacional. Al 2015 , el $51.7 \%$ de los recursos que recibieron las municipalidades para gestionar sus territorios provinieron de estas transferencias (INEI 2017).

En la provincia de Lima, la gran segregación socioeconómica territorial, asociada a la excesiva cantidad de distritos (43), ha golpeado de manera negativa a las cuentas municipales. Bases tributarias pequeñas y muy desiguales, costos administrativos elevados, bajas economías de escala para la prestación de servicios y dificultades en la coordinación intermunicipal para la construcción de infraestructura vial son algunos de los efectos de esta tendencia (Banco Mundial 2015).

Los limitados recursos disponibles para las municipalidades colisionan con la mayor cantidad de funciones que deben desempeñar a partir del proceso de descentralización. Las iniciativas privadas, en este sentido, aparecen como una alternativa para satisfacer las demandas de servicios urbanos (Stiglich 
2012). Sin embargo, nos encontramos frente a un escenario en donde los objetivos son altamente corruptibles debido a que dependen de procesos políticos relativamente cerrados y con altos niveles de asimetría de poder.

El arreglo de gobernanza urbana en Lima está marcado por esta paradoja. Las normas del mercado estarían mediando las relaciones entre las distintas instituciones e individuos, haciendo prevalecer criterios de valor de suelo relacionados más a su potencial para la generación de rentas que a la función pública del espacio.

Este modelo de gobernanza urbana daría mayor peso a las iniciativas privadas y sus demandas de cambio de uso de suelo que a las demandas específicas de las personas de cada territorio, por parques por ejemplo (Hidalgo y Janoschka 2014). Además, estas lógicas operan en alianza con el gobierno distrital que intenta legitimar estos cambios de uso de suelo apelando a la «modernidad» y el «progreso» como lo hemos podido en ver en los casos del Parque Manhattan y Alameda Los Incas.

Quizás la expresión más clara de la manera como entra en funcionamiento el arreglo de gobernanza urbana de Lima se aprecia en la implementación del Decreto Legislativo $\mathrm{N}^{\circ} 1224^{14}$ (Ley marco de la promoción de la inversión privada mediante asociaciones público-privadas y proyectos en activos) en la gestión municipal.

El DL $\mathrm{N}^{\circ} 1224$ ha provisto a las municipalidades de un marco legal que, si bien fue inicialmente diseñado para el desarrollo de proyectos de infraestructura a gran escala, hoy se ha naturalizado como el sustento jurídico para el desarrollo de plataformas comerciales, estacionamientos y otras formas de aprovechamiento privado sobre espacios públicos.

\footnotetext{
${ }^{14}$ En reemplazo del Decreto Legislativo № 1012 que aprobaba la Ley maco de asociaciones público-privadas para la generación de empleo productivo y dictaba normas para la agilización de los procesos de promoción de la inversión privada.
} 
El DL No 1224 permite a las municipalidades ejercer directamente el rol de organismo promotor de la inversión privada a través de un Comité de Inversiones designado por el Concejo Municipal (Artículo 6). Sobre esta característica, vale la pena resaltar que la composición de los concejos municipales es de mayoría del alcalde elegido, con lo cual se espera tener poca o nula oposición a cualquier propuesta sea promovida por el alcalde.

El DL también exige mantener el carácter confidencial y reservado de las iniciativas privadas presentadas, bajo responsabilidad, hasta la declaración de interés (Artículo 33). Si transcurrido el plazo de noventa días calendario desde la publicación de la declaratoria de interés por el Concejo Municipal, y un tercero no manifiesta su interés en la ejecución del proyecto, se procede a la adjudicación directa a favor del proponente de la iniciativa privada (Artículo 35).

En los casos vistos, el Artículo 33 es percibido por los vecinos y vecinas como un mecanismo poco transparente. Incluso, es motivo de acusaciones de corrupción en contra de los alcaldes. Se admite "confidencialmente" a consideración iniciativas privadas que no son de un uso conforme a la zonificación y normativa vigente de las áreas donde se desean desarrollar. Asimismo, el plazo para recibir propuestas alternativas establecido por el Articulo 35 (90 días), resultará siempre corto si se tiene en cuenta que las iniciativas privadas que llegan a ser declaradas de interés han sido previamente negociadas entre la municipalidad y la empresa durante aproximadamente un año. En el caso del Parque Manhattan, pasó más de un año entre que la iniciativa fue presentada (febrero 2015) y declarada de interés (setiembre 2016). En el caso de la Alameda Los Incas pasó poco menos de un año entre que se presentó la iniciativa (julio 2015) y se realizó la consulta vecinal (julio 2016), se desestima en setiembre de 2016.

\section{La participación por movilización}


Tras el análisis del ordenamiento jurídico podemos concluir que el proceso de cesión de espacios públicos para fines privados se inscribe en un arreglo de toma de decisiones que deja poco margen para la participación de la ciudadanía que utiliza estos espacios. En los casos del Parque Manhattan y la Alameda los Incas, sin embargo, observamos que las limitantes institucionales no han representado un obstáculo para que los vecinos y vecinas reclamen un lugar en las decisiones que se toman sobre sus espacios públicos.

La movilización social urbana en defensa de los espacios públicos es el contrapunto de la narrativa construida a partir de la interpretación que las municipalidades dan a las leyes de promoción de la inversión privada. Y es que las movilizaciones, que bien pueden ser de escala barrial o distrital, se producen en el marco de un nuevo ciclo de protestas urbanas vinculadas a un discurso por el derecho a la ciudad (Dammert y Ramírez 2017; Ramírez Corzo 2017). Se trata de protestas en rechazo a la intención de construir by passes que destruyen alamedas verdes, iniciativas privadas en la superficie de parques, estacionamientos subterráneos que ponen en riesgo sobrevivencia de árboles, ampliación de avenidas que eliminan áreas verdes, entre otros.

Típicamente, la movilización social en contextos urbanos se ha relacionado con el proceso de urbanización y las demandas vinculadas al mismo (vivienda, suelo y servicios). Esta tendencia, sin embargo, adquiere nuevas dimensiones en los últimos años. En espacios desatendidos, las demandas individuales y colectivas son asumidas por organizaciones vecinales conformadas alrededor de problemas específicos de la cotidianidad urbana. Estos movimientos apelan a la acción individual y colectiva para encontrar salidas enfocadas a los problemas alrededor de los cuales fueron organizados (Dammert y Ramírez 2017; Ramírez Corzo 2017).

En este contexto, el poder legislativo atendió la demanda ciudadana por la defensa de espacios públicos a través de acciones de representación, 
fiscalización y legislativa. Esta última se materializó en dos proyectos de Ley. En abril de 2017 se presentaron los proyectos de Ley para la protección y gestión de los espacios públicos (PL $1312^{15}$ y PL 1311). El proceso de elaboración de estos incluyó la participación de diversas organizaciones vecinales y colectivos de defensa de los espacios públicos en Lima. Si bien estos proyectos de Ley tienen su propio proceso a recorrer en el Congreso de la República, ya son elementos que aportan a la discusión sobre la importancia de los espacios públicos en la agenda urbana.

En el caso del Parque Manhattan, la defensa fue liderada por el colectivo Salvemos El Parque Manhattan que se crea a inicios del 2016 y está conformada por vecinos de la Urbanización San Felipe de Comas. El colectivo empezó como un comité elegido en elecciones vecinales y reconocido por la Municipalidad de Comas como co-administradores del parque. La resolución de gerencia de la Municipalidad que les reconocía como comité, fue derogada en setiembre de 2016, al iniciarse el conflicto debido a la iniciativa privada. Sin embargo, el comité continuó funcionando por la defensa del parque y finalmente logró en febrero de 2018, mediante Acuerdo de Concejo, que se desestime la iniciativa privada.

La movilización del comité de vecinos permitió que un regidor de oposición presentara una denuncia ante la Contraloría General de la República por la aprobación de la declaración de interés de la iniciativa privada. A raíz de la denuncia, el Órgano de Control Institucional de la Municipalidad de Comas emitió un informe de acción de control simultáneo (simultáneo ya que aún no se ha firmado el contrato entre la empresa y la municipalidad). El informe identificó dos riesgos: la Municipalidad no podía otorgar en uso y declarar de interés una iniciativa sobre el parque ya que no se había realizado el saneamiento físico-legal del terreno; y el precio por metro cuadrado por el derecho de superficie del referido proyecto de iniciativa privada Parque

\footnotetext{
15 El proyecto de Ley 1312, para la protección de espacios públicos tiene por objeto establecer el marco normativo y lineamientos generales para la protección y manejo de los espacios públicos en las ciudades peruanas.
} 
Manhattan se encontraba por debajo de los valores arancelarios establecidos por el Ministerio de Vivienda.

Este informe, si bien ayudó a reforzar la acción de defensa de los vecinos en los medios de comunicación, pudo haber observado más elementos de la iniciativa. Por un lado, el Órgano de Control no tomó en cuenta la naturaleza jurídica del bien, de uso y dominio público, que se quería otorgar en uso por cuarenta años para la realización del proyecto Nuevo Manhattan, el cual restringiría el uso público del parque. La observación tampoco tomó en cuenta la zonificación de este predio, que es Zona de Recreación Pública. Por otro lado, la observación sobre el precio del metro cuadrado partía del principio equivocado de que los valores del espacio público (un parque) podrían medirse en valores comerciales. El parque, al tener una finalidad pública, no debería estar sujeto a una medición de intereses privados.

En el caso de la Alameda Los Incas, la defensa empezó cuando se difundió información de que la iniciativa había sido presentada a la Municipalidad de Independencia. La movilización fue liderada por la Asociación de Propietarios de la Urbanización Tahuantinsuyo “APUT", vecinos directos de la alameda. En junio de 2016 realizaron una marcha desde la Alameda hasta la Municipalidad de Independencia en rechazo a la iniciativa privada. Es a través de la presión que ejercen los vecinos a través de asambleas públicas en la misma alameda, marchas y declaraciones en los medios, que la Municipalidad decide convocar a una consulta vecinal y someter a votación la iniciativa privada, a pesar que la norma no lo pedía. Tras la constante defensa de los vecinos por este espacio público, la Municipalidad de Independencia decidió desestimar la iniciativa privada, a través de Acuerdo de Concejo de setiembre de 2016.

Ambas movilizaciones de vecinos, tanto del Parque Manhattan como de la Alameda, realizaron diversas acciones en defensa de sus espacios públicos. Entre ellas: la organización y sensibilización de sus vecinos, la promoción de actividades artísticas, culturales y deportivas en el parque y la alameda, 
vigilancia del estado de la limpieza pública y del riego de las áreas verdes, movilización de autoridades y funcionarios sectoriales y uso de la función de representación del Congreso de la República. Estas acciones empezaron a nivel de sus respectivas urbanizaciones pero luego se fueron articulando a plataformas distritales y hasta metropolitanas.

Finalmente, estos casos de iniciativas privadas en espacios públicos deben llevarnos también a la reflexión sobre las desigualdades de acceso a espacios públicos en Lima. Se espera que el proceso de consolidación de las urbanizaciones de la «ciudad popular» traiga consigo el mejoramiento de las condiciones de habitabilidad, como el acceso a los principales servicios básicos y equipamientos urbanos (Barreda y Ramírez Corzo 2004). Sin embargo, muchas de estas urbanizaciones aún se encuentran lejos de alcanzar un nivel de provisión de espacios públicos similar al de las urbanizaciones de clase media y alta.

Como aproximación a la provisión de espacios públicos, se puede considerar la información de áreas verdes públicas en Lima por distritos (PLAM 2014). Según estos datos, el distrito de Comas cuenta con $3.9 \mathrm{~m}^{2}$ de áreas verdes por habitante, mientras que Independencia tiene solo $1.2 \mathrm{~m}^{2}$ por habitante, la metrópoli Lima-Callao cuenta en promedio con $3.6 \mathrm{~m}^{2}$ por habitante. Los distritos de San Isidro y Miraflores, que concentran gran parte de las familias de altos ingresos, cuentan con $18.2 \mathrm{~m}^{2}$ y $13.6 \mathrm{~m}^{2}$ de áreas verdes por habitante respectivamente. Siendo el uso y disfrute de los espacios públicos tan importantes para el bienestar de las personas, la desigual provisión de áreas verdes públicas impacta negativamente en la calidad de vida de miles de limeños. En consecuencia, se esperaría que las Municipalidades y todas las entidades públicas tuvieran este tipo de consideraciones para dejar de promover iniciativas que restan el metraje de áreas verdes en sus distritos. 


\section{Reflexiones para la ciudad a partir de las iniciativas privadas en espacios públicos}

El análisis sobre los conflictos generados por la promoción de iniciativas comerciales privadas sobre espacios públicos nos ha mostrado que tanto la regulación pública como las lógicas de inversión del capital condicionan el comportamiento de gobiernos locales y movimientos ciudadanos. Este comportamiento se ve influenciado por asimetrías que poder que persisten en el arreglo de toma de decisiones urbanas (también llamada gobernanza urbana) sobre el suelo de uso público.

Los dos casos - el Parque Manhattan y la Alameda Los Incas - presentan conflictos que cuestionan cómo es que bajo el actual arreglo de gobernanza urbana se privilegia la participación del gobierno local y las empresas privadas. En este sentido, se deja de lado la voz de los vecinos en la gestión de sus espacios públicos y, por ende, de sus barrios. La gobernanza urbana en Lima estaría marcada por las normas del mercado que median las relaciones entre las distintas instituciones e individuos, haciendo prevalecer criterios de valor de suelo relacionados más a su potencial para la generación de rentas que a la función pública de espacios como parques y alamedas.

A pesar de que las iniciativas privadas se han convertido en un actor de peso en el desarrollo de la ciudad en Lima, los casos también demuestran el poder de la movilización ciudadana para contrarrestar esta tendencia. Las movilizaciones se activaron en el momento que los vecinos y vecinas comprobaron que las iniciativas privadas podrían restringir el uso de recreación pública que ejercen sobre sus espacios públicos verdes. Este resultado demostraría que se mantiene un sentido socialmente compartido del espacio público.

A través del análisis de los casos, hemos podido evidenciar cómo la dimensión espacial de la política de promoción de la inversión privada, así no se trate de una política específicamente urbana, genera impactos sobre los 
barrios y la ciudad en general (Sassen 2007). Se puede decir que el DL N ${ }^{\circ}$ 1224 no fomenta explícitamente la eliminación de espacios públicos por centros comerciales pero la evidencia demuestra que este marco legal tampoco lo impide. Por ello, este marco debería adecuar los criterios por los cuales se evalúa a las iniciativas privadas, los criterios deben ser coherentes con el marco legislativo de los bienes de uso y dominio público, no actuar por encima de este. De manera más urgente, debería eliminarse la posibilidad de admitir iniciativas privadas a costa de la disminución de áreas de espacio público verde, que además ya son escasas en ciudades como Lima.

La evidencia sugeriría que el ordenamiento jurídico actual no estaría tomando en consideración las dinámicas del mercado de suelo que ocurren en ciudades como Lima, donde el suelo urbano disponible ya no es abundante y genera una mayor presión de uso sobre los espacios públicos. En este contexto, es aún más importante conservar los espacios públicos con los que cuenta la ciudad y encontrar nuevas formas de ampliar estas áreas importantes de recreación pública.

Como reflexión final, vale la pena señalar que este nuevo ciclo de protestas urbanas abre un espacio para discutir una nuevo modelo de hacer ciudad, donde se pongan en debate los mecanismos de financiamiento para las infraestructuras que se necesitan, la valoración de los espacios públicos y el rol de la participación ciudadana. Es necesario plantear alternativas frente a un modelo de gobernanza urbana de procesos políticos relativamente cerrados y con altos niveles de asimetría de poder que ha demostrado ir en desmedro de lo público. Las alternativas deberán incluir instrumentos que funcionen como mediadores para balancear el desequilibrio de poder entre el capital privado, gobiernos locales y la ciudadanía. Así también, considerar la revalorización de la planificación como acción pública y participativa. 


\section{Bibliografía}

Banco Mundial (2015) Perú - Hacia Un Sistema de Ciudades: Una

Nueva Visión Para Crecer. Lima. Recuperado el 21 de abril de 2018 de

http://documentos.bancomundial.org/curated/es/98121146819615240 2/pdf/101383-REVISED-PUBLIC-SPANISH-ciudadesweb.pdf

Barreda, José, y Daniel Ramírez Corzo (2004) "Lima: Consolidación y Expansión de Una Ciudad Popular." Perú Hoy. "Las ciudades en el Perú" (6): 199-218. Recuperado el 15 de abril de 2018 de http://www.desco.org.pe/recursos/site/files/CONTENIDO/3/07BARR EDA_RAMIREZCORZO.PDF

Borja, Jordi (2012) "Revolución Urbana y Derechos Ciudadanos: Claves Para Interpretar Las Contradicciones de La Ciudad Actual." Universidad de Barcelona. Recuperado de http://www.tdx.cat/handle/10803/83360

Cabrera, Teresa y Miguel Villaseca (2007) Presentes Pero Invisibles:

Mujeres y Espacio Público En Lima Sur. Serie Estu. Lima: Desco.

Dammert, Manuel, y Tania Ramírez (2017) "Retos y Perspectivas Del

Derecho a La Ciudad En Lima." Perú Hoy. "Desarrollo con derechos. Acceso a la dignidad": 117-232.

Fernández de Córdova, Graciela (2012) "Nuevos Patrones de

Segregación Socio-Espacial En Lima y Callao 1990-2007: Nuevos Desafíos Para La Metrópoli." Cuadernos Arquitectura y Ciudad (15): 83. Recuperado el 15 de abril de 2018 de http://repositorio.pucp.edu.pe/index/bitstream/handle/123456789/357 03/CUADERNOS\%2015_edici\%C3\%B3n\%20digital.pdf?sequence= $\underline{1 \& \text { isAllowed }=\mathrm{y}}$ 
Gonzales De Olarte, Efraín, y Juan Manuel Del Pozo (2012) "Lima, Una Ciudad Policéntrica. Un Análisis a Partir de La Localización Del Empleo." Investigaciones Regionales (23): 29-52. http://old.aecr.org/images//ImatgesArticles/2012/10/Gonzales.pdf (15 de abril de 2018).

Hidalgo, Rodrigo y Michael Janoschka (2014) "La Ciudad Neoliberal:

Estímulos de Reflexión Crítica." En La Ciudad Neoliberal. Gentrificación y Exclusión. Rodrigo Hidalgo y Michael Janoschka (eds). Santiago de Chile: Pontificia Universidad Católica de Chile, 732.

INEI (2017) Perú: Estadísticas Municipales 2016. Lima.

Ortiz, Iván (2017) "Introducción al derecho urbanístico". Lima:

Pontificia Universidad Católica del Perú.

Parodi, Carlos (2005) "Perú 1960-2000: políticas económicas y sociales en entornos cambiantes". Lima: Centro de Investigación de la Universidad del Pacífico.

Ramírez Corzo, Daniel (2017) "Revuelta Urbana y Derecho a La

Ciudad: Más Allá de La Ciudad Popular.” Ojo Zurdo: 13-16.

Sassen, Saskia (2007) "El Reposicionamiento de Las Ciudades y

Regiones Urbanas En Una Economía Global: Ampliando Las Opciones de Política y Gobernanza." Eure Vol. XXXII: 9-34. https://doi.org/10.4067/s0250-71612007000300002

Stiglich, Matteo (2012) "La Planificación Privada Aplasta La Inclusión.” Quehacer. "Entran en la foto" (188): 96-101. Recuperado el 15 de abril de 2018 de http://www.desco.org.pe/recursos/sites/indice/837/3781.pdf 